\title{
Systemic inflammation in chronic obstructive pulmonary disease: a population-based study
}

\author{
Francisco Garcia-Rio*1, Marc Miravitlles², Joan B Soriano³ ${ }^{3}$ Luis Muñoz ${ }^{4}$ Enric Duran-Tauleria5 ${ }^{5}$ Guadalupe Sánchez ${ }^{6}$, \\ Víctor Sobradillo7, Julio Ancochea ${ }^{8}$ and EPI-SCAN Steering Committee
}

\begin{abstract}
Background: Elevated circulating levels of several inflammatory biomarkers have been described in selected patient populations with COPD, although less is known about their population-based distribution. The aims of this study were to compare the levels of several systemic biomarkers between stable COPD patients and healthy subjects from a population-based sample, and to assess their distribution according to clinical variables.

Methods: This is a cross-sectional study design of participants in the EPI-SCAN study (40-80 years of age). Subjects with any other condition associated with an inflammatory process were excluded. COPD was defined as a post-

bronchodilator $\mathrm{FEV}_{1} / \mathrm{FVC}<0.70$. The reference group was made of non-COPD subjects without respiratory symptoms, associated diseases or prescription of medication. Subjects were evaluated with quality-of-life questionnaires, spirometry and 6-minute walk tests. Serum C-reactive protein (CRP), tumor necrosis factor (TNF)-a, interleukins (IL-6 and IL-8), alpha1-antitrypsin, fibrinogen, albumin and nitrites/nitrates (NOx) were measured.

Results: We compared 324 COPD patients and 110 reference subjects. After adjusting for gender, age, BMl and tobacco consumption, COPD patients showed higher levels of CRP ( $0.477 \pm 0.023$ vs. $0.376 \pm 0.041 \mathrm{log} \mathrm{mg} / \mathrm{L}, p=0.049)$, TNF-a $(13.12 \pm 0.59$ vs. $10.47 \pm 1.06 \mathrm{pg} / \mathrm{mL}, \mathrm{p}=0.033)$, LL-8 (7.56 \pm 0.63 vs. $3.57 \pm 1.13 \mathrm{pg} / \mathrm{ml} ; \mathrm{p}=0.033)$ and NOx $(1.42 \pm 0.01$ vs. $1.36 \pm 0.02 \mathrm{log} \mathrm{nmol} / \mathrm{l} ; \mathrm{p}=0.048$ ) than controls. In COPD patients, serum concentrations of some biomarkers were related to severity and their exercise tolerance was related to serum concentrations of CRP, IL-6, IL-8, fibrinogen and albumin.
\end{abstract}

Conclusions: Our results provide population-based evidence that COPD is independently associated with low-grade systemic inflammation, with a different inflammatory pattern than that observed in healthy subjects.

\section{Background}

Chronic obstructive pulmonary disease (COPD) is associated with important extrapulmonary manifestations, including weight loss, skeletal muscle dysfunction, cardiovascular disease, depression, osteoporosis, reduced exercise tolerance, and poor health status [1,2]. Although the pathobiologyof COPD has not been fully determined, systemic inflammation has been implicated in the pathogenesis of the majority of these systemic effects [3], to the point that some authors have suggested that COPD is a part of a chronic systemic inflammatory syndrome [4].

The association between systemic inflammation and COPD has mostly been evaluated in highly selected

* Correspondence: fgr01m@gmail.com

1 Pneumology Service, Hospital Universitario La Paz, IdiPAZ, Madrid, Spain Full list of author information is available at the end of the article patient samples, which have shown activation of circulating inflammatory cells and increased levels of proinflammatory cytokines and acute-phase reactants as well as increased oxidative stress [5-7]. The limitations derived from the small size and partial scope of most of these studies led to the completion of a meta-analysis, which compiled the main current evidence supporting the presence of systemic inflammation in stable COPD patients [8]. Nevertheless, there were remarkable differences in the selection of subjects and the definitions of COPD employees were neither homogeneous nor adapted to current guidelines [9]. In the population-based studies included in this analysis, COPD diagnosis was assumed in participants in the lowest quartile of predicted $\mathrm{FEV}_{1}$, and those subjects in the highest quartile of predicted $\mathrm{FEV}_{1}$ were taken as controls. The controversy has been 
reinforced by another recent meta-analysis that did not find statistically significant differences in either serum Creactive protein (CRP) or tumour necrosis factor (TNF)$\alpha$ concentrations between healthy subject groups and any of the COPD stages [10].

In contrast, an inverse association between higher levels of circulating inflammation-sensitive proteins, including CRP, interleukin (IL)- 6 and alpha-1 antitrypsin (A1AT), and lower spirometric values has been described in several samples of middle-aged to older general population [11-13]. Moreover, it has recently been reported that increased serum levels of CRP are associated with an increase risk of developing COPD in a population-based sample of smokers [14].

In the population-based Epidemiologic Study of COPD in Spain (EPI-SCAN) we have compared serum levels of several biomarkers between stable COPD patients and healthy subjects trying to analyse the contribution of possible confounding factors to the development of systemic inflammation. We selected the following biomarkers: CRP, TNF- $\alpha$, IL-6, IL-8, alpha-1 antitrypsin (A1AT), fibrinogen, albumin and nitrites/nitrates (NOx), because they have been more widely studied in COPD and they have shown some relationship with either its prognosis and/or the development of cardiovascular complications. We have also evaluated the relation between systemic biomarkers and pulmonary function, exercise tolerance and health-related quality of life in COPD patients derived from the general population.

\section{Methods}

\section{Study design and participants}

The present study is part of the EPI-SCAN study, a multicentre, cross-sectional, population-based, observational study conducted at 11 sites throughout Spain $[15,16]$. The final population recruited was formed by 4,274 non-institutionalized participants from $40-80$ years old. The study was approved by the corresponding ethics committees and all participants gave written informed consent.

In accordance with current GOLD guidelines, COPD was defined by a postbronchodilator $\mathrm{FEV}_{1} / \mathrm{FVC}$ ratio < 0.70 [9]. COPD severity was determined by the GOLD criteria and the BODE index $[9,17]$. Subjects with a postbronchodilator $\mathrm{FEV}_{1} / \mathrm{FVC}$ ratio $\geq 0.70$ were considered not to have COPD.

All participants classified as COPD were selected for the systemic biomarker analysis. To avoid excessive testing of the non-COPD study population, an equal number of non-COPD subjects were consecutively selected in each centre. Exclusion criteria for this analysis included a previous diagnosis of acute myocardial infarction, angina, congestive heart failure, cancer, hepatic cirrhosis, chronic renal failure, rheumatoid arthritis or any other systemic inflammatory disease. In addition, specific exclusion cri- teria from the non-COPD cohort were any respiratory symptoms as per the European Coal and Steel Community (ECSC) questionnaire, any associated concomitant disease, and regularly prescribed medications. The reference group obtained after applying these selection criteria was considered to be of healthy subjects.

\section{Procedures}

Fieldwork and all methods have been described previously $[15,16]$. Self-reported exposure was identified initially through a questiondeveloped for the European Community Respiratory Health Survey: "Have you ever worked in a job which exposed you to vapors, gas, dust, or fumes?" The question was followedby a list of 23 individual exposures considered a priori risk factors for COPD, subsequently grouped into three categories: biological dusts, mineral dusts and gases or fumes. Baseline dyspnea was assessed by the Modified Medical Research Council (MMRC) scale, and subjects completed the ECSC questionnaire of respiratory symptoms, the London Chest Activity of Daily Living (LCADL) scale, the EQ-5D questionnaire and the St. George's Respiratory Questionnaire.

Blood samples were collected using standardized procedures and stored at $-80^{\circ} \mathrm{C}$. Samples were shipped to a single laboratory (Hospital Clinic, Barcelona) for centralized analysis approximately every 2 months. TNF- $\alpha$, IL- 6 and IL-8 were determined in duplicate with a high sensitivity enzyme-linked immunosorbent assay (Biosource, Nivelles, Belgium) with lower detection limits of $3 \mathrm{pg} / \mathrm{ml}$ for total TNF- $\alpha, 2 \mathrm{pg} / \mathrm{ml}$ for IL- 6 and $0.7 \mathrm{pg} / \mathrm{ml}$ for IL- 8 . The intra-assay coefficients of variation were $3.7 \%$ for TNF- $\alpha, 2.2 \%$ for IL- 6 and $2.3 \%$ for IL-8. C-reactive protein (CRP) was assessed by latex-enhanced immunonephelometry (Siemens, Dublin, Ireland) with a lower detection limit of $0.4 \mathrm{mg} / \mathrm{l}$ and an intra-assay coefficient of variation of $1.2 \%$. Alpha-1 antitrypsin (A1AT) was measured by a particle-enhanced immunonephelometry (Siemens, Malburg, Germany), with detection limits ranged from 0.0095 to $0.3040 \mathrm{~g} / \mathrm{l}$ and an intra- and interassay variability or $3.9 \%$ and $2.0 \%$, respectively.

Albumin levels were estimated by the bromocresol green method (Siemens, Dublin, Ireland), with a detection limits from 10 to $60 \mathrm{~g} / \mathrm{l}$ and an intra-assay coefficient of variation of $1.5 \%$. Fibrinogen was assessed using a coagulation analyzer (Roche, Mannheim, Germany) according to the Clauss method and calculated from ethylenediamine tetra-acetic acid to citrate plasma values. The detection range was 0.5 to $12.0 \mathrm{~g} / \mathrm{L}$ and the intraassay variability $2.8 \%$. Nitrites and nitrates (NOx) were determined by a chemiluminescence detector in an NO analyser (Sievers Instruments, Inc., Boulder, CO, USA). The lower detection limit was $1 \mathrm{pmol}$ and the intra-assay coefficient of variation was $10 \%$. 
Baseline and post-bronchodilator spirometries were performed at each site using the same equipment according to current recommendations [18]. The predicted values used were those of the Spanish reference population [19]. A 6-min walk test was performed twice, with an interval between testing of 30 minutes, according to the ATS guidelines [20].

\section{Analysis}

Variables are presented as a percentage, mean \pm SD or median (interquartile range) as required depending on their distribution. Statistical analysis was performed with SPSS 14.0 for Windows (SPSS, Inc., Chicago, IL) and with SAS statistical package (version 9.1, Cary, NC). A twosided $\mathrm{p}$ value $<0.05$ was considered statistically significant.

Pearson's chi-square test, Mann-Whitney U test or Student's $\mathrm{t}$ test were used for two-group comparisons, depending on data distribution. The effect of the possible confounding factors was assessed using generalised linear model analysis [21]. In this analysis, a logarithmic transformation was used in those variables to reduce their skewness. We constructed a multivariate model, including group and gender as fixed factors and age, BMI and smoking history as a dichotomous variable ( $\geq 10$ packyears, yes/no) as covariates. The link function used was the identity. For each systemic biomarker, we chose the normal distribution because it was more fitting than inverse Gaussian or gamma distribution, according to the plausibility criteria, Pearson's chi-square and analysis of deviance. Comparisons by differing severity within the COPD group were performed using ANOVA analysis, with post-hoc analysis by the Bonferroni test. In the COPD group, the correlations between the serum levels of systemic biomarkers and the clinical and functional parameters were estimated using Pearson's linear bivariate correlation coefficient.

Data are presented according to current recommendations for observational studies in epidemiology (STROBE).

\section{Results}

A total of 3,802 subjects were evaluated. From 386 subjects identified with COPD according to GOLD, 12 refused blood extraction and 50 were excluded due to evidence of comorbidity, leaving 324 subjects in the COPD group for analysis. Of 373 consecutively-selected subjects without COPD, 250 were excluded due to respiratory symptoms and 13 for evidence of comorbidity, rendering 110 subjects in the control group (Figure 1).

Participant characteristics are described in Table 1. In comparison with the reference group, there were more men and smokers, of greater smoking intensity, who were older, with higher body mass index in the COPD group.
There was a wide range of COPD severity in our cohort, although only $23 \%$ of these patients were taking inhaled corticosteroids. Table 2 shows the occupational exposure characteristics of the patients included in the COPD group.

The crude comparison of serum level biomarkers showed that COPD participants had higher concentrations of CRP, TNF- $\alpha$, IL- 6 , IL-8, alpha-1 antitrypsin, fibrinogen and nitrites/nitrates than control subjects (Figure 2). On the contrary, albumin concentration was non-significantly decreased $(\mathrm{p}=0.061)$.

Table 3 shows the estimates obtained from generalized linear models with gender, age, BMI, pack-years and group as dependent variables. After adjusting for these covariates, group dependence was retained for CRP, TNF- $\alpha$, IL- 8 and nitrites/nitrates, with a positive effect on their serum concentrations. After adjustment for gender, age, BMI and pack-years, COPD participants presented higher levels of log CRP (mean \pm mean standard error) $(0.477 \pm 0.023$ vs. $0.376 \pm 0.041 \log \mathrm{mg} / \mathrm{L}, \mathrm{p}=$ $0.049)$, TNF $-\alpha(13.12 \pm 0.59$ vs. $10.47 \pm 1.06 \mathrm{pg} / \mathrm{mL}, \mathrm{p}=$ $0.033)$, IL-8 (7.56 \pm 0.63 vs. $3.57 \pm 1.13 \mathrm{pg} / \mathrm{ml} ; \mathrm{p}=0.033)$ and nitrites/nitrates (1.42 $\pm 0.01 \mathrm{vs.} 1.36 \pm 0.02 \mathrm{log} \mathrm{nmol} /$ $1 ; p=0.048)$. No differences for adjusted levels of alpha-1 antitrypsin, IL-6, fibrinogen or albumin were found between COPD and reference subjects (Figure 3).

Serum concentrations of several systemic biomarkers were mostly higher in severe COPD than in moderate or mild COPD. Of interest, these differences with biomarker concentrations were not concordant with severity assessed by GOLD and the BODE index (Tables 4 and 5), and the biomarkers most consistent for the severity discrimination were CRP, IL-6 and nitrites/nitrates.

In COPD participants, a relationship between systemic biomarker concentrations and health status scores was found. Dyspnea intensity, assessed by the MMRC, was weakly related to CRP $(r=0.133, p=0.027)$ and to fibrinogen concentrations $(r=0.131, p=0.021)$. A weak relationship between the symptoms domain of the SGRQ and the IL-8 serum concentration was noted $(\mathrm{r}=0.112, \mathrm{p}=$ 0.049), while the activity domain was related with CRP $(r$ $=0.164, \mathrm{p}=0.006)$, IL-6 $(\mathrm{r}=0.117, \mathrm{p}=0.039)$, fibrinogen $(\mathrm{r}=0.158, \mathrm{p}=0.006)$ and albumin $(\mathrm{r}=-0.140, \mathrm{p}=0.014)$. Indeed, CRP level was also weakly related to the visual analogue scale score $(\mathrm{r}=-0.146, \mathrm{p}=0.015)$ and utility score in the EQ-5D $(r=-0.121, p=0.045)$. Biomarker serum concentrations also showed a weak relationship with the functional characteristics of COPD patients. Post-bronchodilator $\mathrm{FEV}_{1}$ was inversely related to CRP ( $\mathrm{r}$ $=-0.142, \mathrm{p}=0.018)$ and to IL-6 $(\mathrm{r}=-0.190, \mathrm{p}=0.023)$. In the same way, we found a weak relationship between exercise tolerance and serum concentrations of CRP $(r=-$ 0.167, $\mathrm{p}=0.007), \mathrm{IL}-6(\mathrm{r}=-0.174, \mathrm{p}=0.003), \mathrm{IL}-8(\mathrm{r}=$ - 
Subjects randomly contacted

$(n=4,274)$

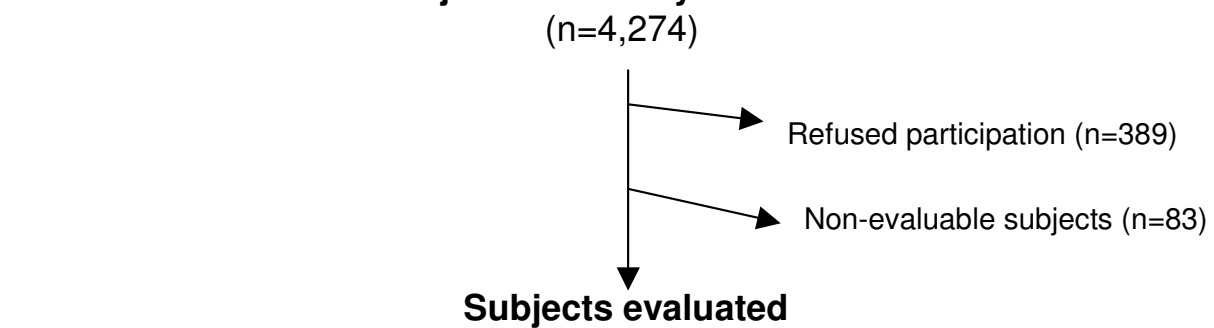

$(\mathrm{n}=3,802)$

Non-COPD subjects

$(n=3,416)$

COPD subjects

consecutive selection

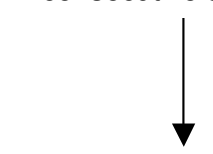

extraction $(n=12)$

\section{Non-COPD subjects}

with blood sample

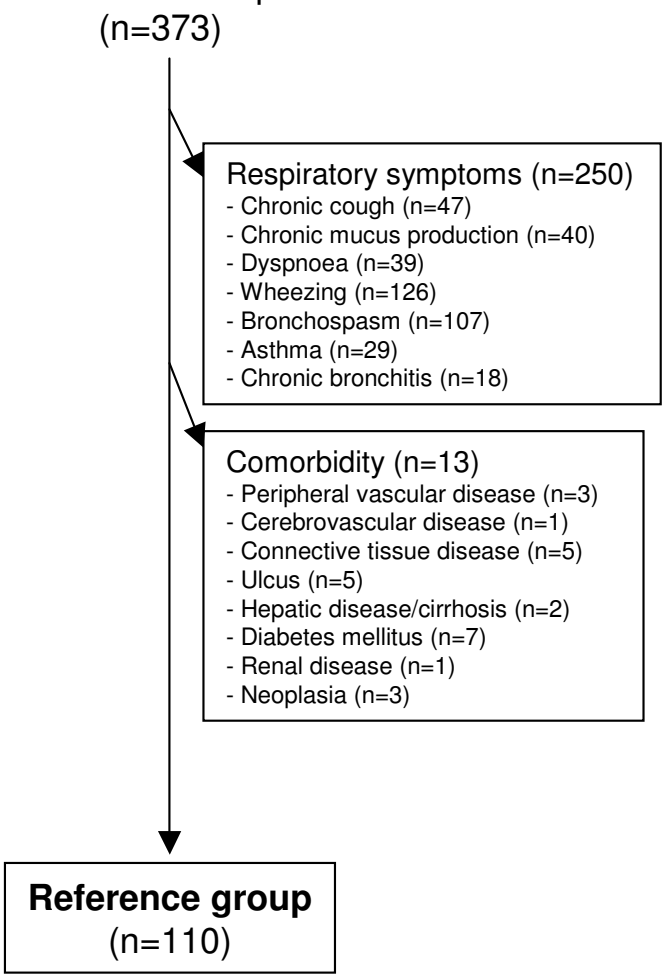

Comorbidity $(n=50)$

- Ischemic cardiac disease $(n=11)$

- Chronic heart failure $(n=10)$

- Connective tissue disease $(n=2)$

- Hepatic disease/cirrhosis $(n=2)$

- Diabetes mellitus $(n=12)$

- Renal disease $(n=2)$

- Chronic mucus production $(n=40)$

- Neoplasia $(n=11)$

Figure 1 Flow-chart for the constitution of study groups 
Table 1: General characteristics of the study groups.

\begin{tabular}{|c|c|c|c|}
\hline & $\begin{array}{c}\text { COPD group } \\
(n=324)\end{array}$ & $\begin{array}{l}\text { Reference group } \\
\quad(n=110)\end{array}$ & $p$ \\
\hline Male gender & $241(74 \%)$ & $51(46 \%)$ & $<0.0001$ \\
\hline Age (years) & $64(10)$ & $55(10)$ & 0.0001 \\
\hline Smoking status & & & $<0.0001$ \\
\hline Never smoker & $67(21 \%)$ & $66(60 \%)$ & \\
\hline Former smoker & $138(43 \%)$ & $30(27 \%)$ & \\
\hline Current smoker & $119(37 \%)$ & $14(13 \%)$ & \\
\hline Smoking exposure (pack-years) & $40(25-55)$ & $10(5-30)$ & $<0.0001$ \\
\hline Body mass index $\left(\mathrm{Kg} / \mathrm{m}^{2}\right)$ & $27.9(4.8)$ & $26.1(3.4)$ & 0.001 \\
\hline Education level & & & 0.130 \\
\hline Less than primary school & $53(16 \%)$ & $9(8 \%)$ & \\
\hline Primary school & $120(37 \%)$ & $41(37 \%)$ & \\
\hline Secondary school & $84(26 \%)$ & $40(36 \%)$ & \\
\hline University degree & $62(19 \%)$ & $20(18 \%)$ & \\
\hline \multicolumn{4}{|l|}{ Current treatment } \\
\hline Short-acting beta-agonist & $57(18 \%)$ & 0 & 0.0001 \\
\hline Long-acting beta-agonist & $68(21 \%)$ & 0 & 0.0001 \\
\hline Anticholinergic & $52(16 \%)$ & 0 & 0.0001 \\
\hline Methylxantines & $7(2 \%)$ & 0 & 0.127 \\
\hline Inhaled corticosteroids & $75(23 \%)$ & 0 & 0.0001 \\
\hline \multicolumn{4}{|l|}{ Pulmonary function } \\
\hline FVC (L) & $3.34(1.00)$ & $3.96(1.12)$ & $<0.0001$ \\
\hline FVC (\% of predicted) & $99(22)$ & $119(16)$ & $<0.0001$ \\
\hline $\mathrm{FEV}_{1}(\mathrm{~L})$ & $2.03(0.67)$ & $3.13(0.88)$ & $<0.0001$ \\
\hline $\mathrm{FEV}_{1}(\%$ of predicted $)$ & $77(19)$ & $115(15)$ & $<0.0001$ \\
\hline $\mathrm{FEV}_{1} / \mathrm{FVC}$ & $0.61(0.08)$ & $0.79(0.05)$ & $<0.0001$ \\
\hline Postbronchodilator FVC (L) & $3.53(1.01)$ & $3.95(1.10)$ & $<0.0001$ \\
\hline Postbronchodilator FVC (\% of predicted) & $105(21)$ & $119(14)$ & $<0.0001$ \\
\hline Postbronchodilator $\mathrm{FEV}_{1}(\mathrm{~L})$ & $2.18(0.69)$ & $3.19(0.88)$ & $<0.0001$ \\
\hline Postbronchodilator $\mathrm{FEV}_{1}$ (\% of predicted) & $82(20)$ & $117(14)$ & $<0.0001$ \\
\hline Postbronchodilator $\mathrm{FEV}_{1} / \mathrm{FVC}$ & $0.62(0.08)$ & $0.81(0.05)$ & $<0.0001$ \\
\hline Distance walked in 6 minutes $(\mathrm{m})$ & $450(122)$ & $514(108)$ & $<0.0001$ \\
\hline BODE index score & & & $<0.0001$ \\
\hline Quartile $1(0-2)$ & $282(90 \%)$ & $110(100 \%)$ & \\
\hline Quartile 2 (3-4) & $19(6 \%)$ & 0 & \\
\hline Quartile 3 (5-6) & $10(3 \%)$ & 0 & \\
\hline Quartile 4 (7-10) & $2(0.6 \%)$ & 0 & \\
\hline
\end{tabular}


Table 1: General characteristics of the study groups. (Continued)

\begin{tabular}{|c|c|c|c|}
\hline \multicolumn{4}{|c|}{ EQ-5D questionnaire } \\
\hline VAS score & $75(60-85)$ & $85(80.0-93.8)$ & $<0.0001$ \\
\hline Utility score & $0.91(0.83-1.0)$ & $1.0(1.0-1.0)$ & $<0.0001$ \\
\hline \multicolumn{4}{|l|}{ SGRQ } \\
\hline Total & $16.7(6.2-28.6)$ & $1.3(0.0-3.3)$ & $<0.0001$ \\
\hline Symptoms & $19.6(8.8-41.2)$ & $4.3(0.0-9.5)$ & $<0.0001$ \\
\hline Activity & $23.6(6.0-47.7)$ & $0.0(0.0-0.0)$ & $<0.0001$ \\
\hline Impact & $7.6(1.6-19.5)$ & $0.0(0.0-0.0)$ & $<0.0001$ \\
\hline LCADL scale & $15(14-17)$ & $15(15-15)$ & 0.003 \\
\hline
\end{tabular}

0.137, $\mathrm{p}=0.019)$, fibrinogen $(\mathrm{r}=-0.256, \mathrm{p}<0.001)$ and albumin $(\mathrm{r}=0.180, \mathrm{p}=0.002)$ (Figure 4).

\section{Discussion}

This study provides population-based evidence that stable COPD patients have a pro-inflammatory state, with increased circulating levels of many inflammatory cytokines and acute-phase reactants. In addition to the contribution of previously-recognized factors such as age, gender, BMI or smoking, COPD constitutes an independent factor for the elevation of many of the analyzed systemic biomarkers, which in the case of CRP, TNF-alpha, IL-6 and NOx is also dependent on severity. Finally, baseline inflammatory markers show a relation with some domains of health-related quality of life, airflow limitation and exercise tolerance.

\section{Confounding factors}

To adequately evaluate the effect of COPD on systemic biomarkers, several risk factors associated with COPD should be considered. COPD is an age-related disorder and the normal process of aging appears to be associated with a similar low-grade systemic inflammatory process $[16,22]$. The importance of gender is given by the fact that females have a more vigorous inflammatory reaction and generate more oxidative stress in the airways than males
[23]. Although an abnormal systemic inflammatory reaction is detected in most smokers, it has been demonstrated that some systemic biomarkers remain persistently high after smoking cessation [24], suggesting the contribution of other factors. For this reason, some authors propose to evaluate the impact of tobacco on systemic biomarkers depending on whether a dose threshold (10 pack-years) has been reached [25]. Obesity is associated with low-grade systemic inflammation and it has been suggested that the distribution of body compartments might originate a different behaviour of some inflammatory markers $[26,27]$. In concordance with previous reports [28], a direct correlation was found between BMI and CRP $(r=0.242, \mathrm{p}=0.0001)$ in the COPD participants of our study.

\section{Systemic biomarkers in COPD}

After adjusting for possible confounding factors, we report that COPD patients showed higher levels of TNF$\alpha$, IL-6, IL-8, CRP and nitrites/nitrates than control subjects. The origin of systemic inflammation in COPD is not completely clear. The hypothesis that systemic inflammation is originated by spill over from the pulmonary compartment has not yet been proven [3]. It has been suggested that some common genetic or constitutional factors may predispose individuals with COPD

Table 2: Occupational exposure characteristics of COPD patients by smoking status.

\begin{tabular}{|c|c|c|c|c|}
\hline & Never smoker & Former smoker & Current smoker & $p$ \\
\hline Subjects, n & 67 & 138 & 119 & \\
\hline Self-reported exposure to vapors, gases, dusts or fumes Job exposure & $27(40.3 \%)$ & $54(39.1 \%)$ & $49(41.2 \%)$ & 0.945 \\
\hline Biological dusts & $15(22.4 \%)$ & $56(40.6 \%)$ & $50(42.0 \%)$ & 0.017 \\
\hline Mineral dusts & $24(35.8 \%)$ & 48 (34.8\%) & 37 (31.1\%) & 0.752 \\
\hline Gases or fumes & $33(49.3 \%)$ & $55(39.9 \%)$ & $48(40.3 \%)$ & 0.398 \\
\hline
\end{tabular}

Comparisons between groups by chi-square test 

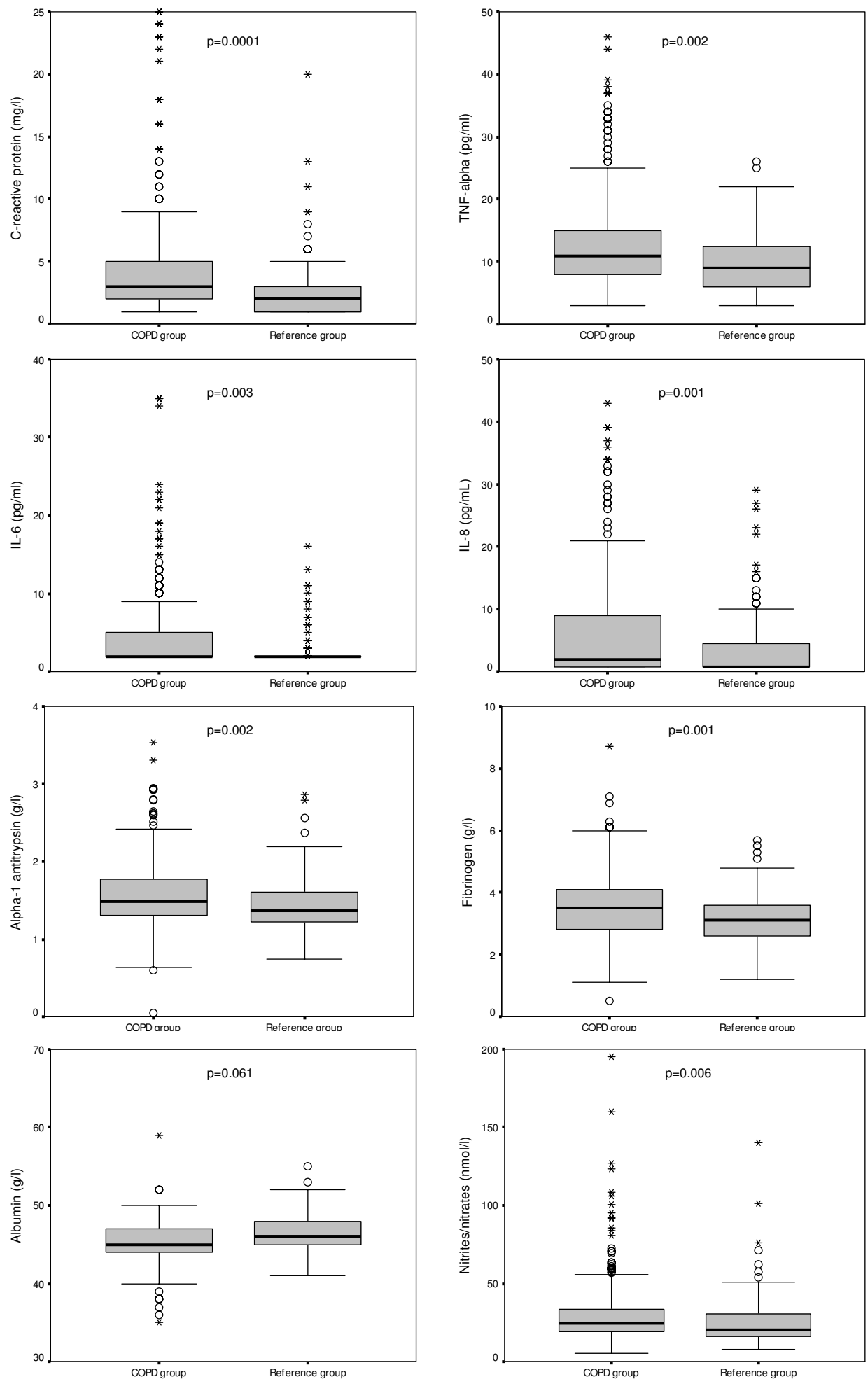

Figure 2 Box-and-whisker plots of the systemic biomarker crude distribution in COPD and reference groups. The top of the box represents the 75 th percentile, the bottom of the box represents the 25 th percentile, and the line in the middle represents the 50 th percentile. The whiskers represent the highest and lowest values that are not outliers or extreme values. Outliers (values that are between 1.5 and 3 times the interquartile range) and extreme values (values that are more than 3 times the interquartile range) are represented by circles and asterisks beyond the whiskers. Abbreviations: TNF = tumor necrosis factor; IL = interleukin. Comparisons between groups by U-Mann-Whitney test or t-Student test depending on the distribution. 
Table 3: Significance of each multivariate model to estimate systemic biomarkers*.

\begin{tabular}{|c|c|c|c|c|}
\hline Biomarker & Parameter & Coefficient (SE) & Wald 95\% Cl & $p$-value \\
\hline \multirow[t]{6}{*}{ C-reactive protein $\dagger$} & Intercept & $-0.44(0.173)$ & $-0.785--0.103$ & 0.011 \\
\hline & Age & $0.005(0.002)$ & $0.001-0.009$ & 0.012 \\
\hline & BMI & $0.019(0.004)$ & $0.011-0.028$ & 0.001 \\
\hline & Smoker & $0.036(0.155)$ & $-0.268-0.340$ & 0.816 \\
\hline & Gender & $-0.004(0.044)$ & $-0.089-0.083$ & 0.936 \\
\hline & COPD group & $0.101(0.049)$ & $0.004-0.198$ & 0.041 \\
\hline \multirow[t]{6}{*}{ TNF-alpha } & Intercept & $6.306(4.301)$ & $-2.151-14.763$ & 0.143 \\
\hline & Age & $0.062(0.049)$ & $-0.034-0.158$ & 0.207 \\
\hline & $\mathrm{BMI}$ & $0.059(0.110)$ & $-0.157-0.276$ & 0.590 \\
\hline & Smoker & $0.810(3.434)$ & $-5.942-7.562$ & 0.814 \\
\hline & Gender & $-0.989(1.088)$ & $-3.128-1.150$ & 0.364 \\
\hline & COPD group & $2.668(1.250)$ & $0.211-5.125$ & 0.033 \\
\hline \multirow[t]{6}{*}{ IL-6 } & Intercept & $3.420(2.477)$ & $-1.450-8.290$ & 0.168 \\
\hline & Age & $0.025(0.028)$ & $-0.030-0.081$ & 0.367 \\
\hline & $\mathrm{BMI}$ & $0.017(0.063)$ & $-0.108-0.142$ & 0.787 \\
\hline & Smoker & $-0.597(1.934)$ & $-4.399-3.204$ & 0.758 \\
\hline & Gender & $-1.525(0.619)$ & $-2.741--0.309$ & 0.014 \\
\hline & COPD group & $1.194(0.713)$ & $-0.207-2.595$ & 0.095 \\
\hline \multirow[t]{6}{*}{ IL-8 } & Intercept & $9.436(4.712)$ & $0.173-18.700$ & 0.046 \\
\hline & Age & $-0.007(0.053)$ & $-0.112-0.098$ & 0.892 \\
\hline & $\mathrm{BMI}$ & $-0.214(0.121)$ & $-0.451-0.024$ & 0.078 \\
\hline & Smoker & $2.951(3.672)$ & $-4.267-10.169$ & 0.422 \\
\hline & Gender & $0.277(1.175)$ & $-2.034-2.587$ & 0.814 \\
\hline & COPD group & $3.995(1.350)$ & $1.342-6.648$ & 0.003 \\
\hline \multirow[t]{6}{*}{ Alpha-1 antitrypsin } & Intercept & $1.307(0.184)$ & $0.947-1.668$ & $<0.001$ \\
\hline & Age & $0.003(0.002)$ & $-0.001-0.007$ & 0.153 \\
\hline & BMI & $0.001(0.005)$ & $-0.011-0.008$ & 0.785 \\
\hline & Smoker & $0.069(0.143)$ & $-0.351-0.213$ & 0.630 \\
\hline & Gender & $0.003(0.046)$ & $-0.087-0.093$ & 0.945 \\
\hline & COPD group & $0.084(0.053)$ & $-0.019-0.187$ & 0.112 \\
\hline \multirow[t]{6}{*}{ Fibrinogen } & Intercept & $0.484(0.416)$ & $-0.335-1.302$ & 0.246 \\
\hline & Age & $0.030(0.005)$ & $0.020-0.039$ & 0.001 \\
\hline & $\mathrm{BMI}$ & $0.021(0.011)$ & $0.000-0.042$ & 0.050 \\
\hline & Smoker & $-0.087(0.325)$ & $-0.726-0.551$ & 0.788 \\
\hline & Gender & $0.344(0.104)$ & $0.139-0.549$ & 0.001 \\
\hline & COPD group & $0.134(0.119)$ & $-0.100-0.369$ & 0.260 \\
\hline
\end{tabular}


Table 3: Significance of each multivariate model to estimate systemic biomarkers*. (Continued)

\begin{tabular}{|c|c|c|c|c|}
\hline \multirow[t]{6}{*}{ Albumin } & Intercept & $50.071(1.165)$ & $47.781-52.361$ & 0.001 \\
\hline & Age & $-0.066(0.013)$ & $-0.092--0.040$ & 0.001 \\
\hline & BMI & $0.028(0.030)$ & $-0.031-0.087$ & 0.350 \\
\hline & Smoker & $-0.083(0.911)$ & $-1.873-1.707$ & 0.928 \\
\hline & Gender & $-0.759(0.290)$ & $-1.329--0.188$ & 0.009 \\
\hline & COPD group & $-0.299(0.333)$ & $-0.955-0.356$ & 0.370 \\
\hline \multirow[t]{6}{*}{ Nitrites/nitrates† } & Intercept & $1.636(0.097)$ & $1.445-1.828$ & 0.001 \\
\hline & Age & $-0.001(0.001)$ & $-0.003-0.001$ & 0.35 \\
\hline & BMI & $-0.004(0.002)$ & $-0.009-0.000$ & 0.116 \\
\hline & Smoker & $-0.007(0.076)$ & $-0.157-0.143$ & 0.926 \\
\hline & Gender & $-0.079(0.024)$ & $-0.127--0.031$ & 0.001 \\
\hline & COPD group & $0.059(0.028)$ & $0.004-0.114$ & 0.034 \\
\hline
\end{tabular}

\footnotetext{
* Main effects of factors and covariates included in the generalized linear model analysis. Smoker was defined as current or former smoker of
} $>10$ packs-year (yes/no). COPD group effect was estimated versus reference group. $\dagger$ Parameter with logarithmic transformation.

towards both systemic and pulmonary inflammation [29]. Lung hyperinflation, tissue hypoxia and skeletal muscle and bone marrow alterations have also been implicated in the induction of systemic inflammation [3].

Although an increased production of NO in COPD patients could constitute a host defense mechanism, a high level of NO can also cause injury and thus contribute to the respiratory and systemic features of the disease. In an inflammatory environment, exaggerated production of NO in the presence of oxidative stress may produce the formation of strong oxidizing reactive nitrogen species, such as peroxynitrite, leading to nitration, which provokes inhibition of mitochondrial respiration, protein dysfunction and cell damage [30]. The activation of various heme peroxidases by hydrogen peroxide can promote oxidation of nitrites to intermediates that are capable of nitrating aromatic substratesand proteins [30].

Although the COPD severity classification according to the BODE index shows a great capacity for discriminating among the systemic biomarker levels, as expected from its multicomponent character, the GOLD classification also shows differences in biomarker levels. However, the selection of a small number of severe patients in our population sample may reduce the strength of a possible association between biomarkers and GOLD stage. In some previous studies, the relation between plasma CRP levels and the severity of the disease has already been suggested [5,31]. De Torres and colleagues reported the usefulness of CRP in predicting clinical and functional outcomes in stable COPD, with similar correlation coefficients to those of our study [27].

Nevertheless, one of the major implications of systemic inflammation in COPD is its contribution to a proathero- sclerotic state. The relationship between COPD, systemic inflammation, and cardiovascular diseases may be especially relevant as over half of patients with COPD die from cardiovascular causes [32]. A Copenhagen City Heart Study cohort study showed that the incidence of COPD hospitalization and COPD death was higher in individuals with baseline CRP above $3 \mathrm{mg} / \mathrm{L}$, with an absolute 10-yr risk for death of 57\% [33]. In fact, it has been suggested that CRP can be considered as the sentinel biomarker [32,33]. Interesting, in our COPD patients, serum CRP levels were related to concentrations of IL-6 $(\mathrm{r}=0.333, \mathrm{p}<0.001)$, IL-8 $(\mathrm{r}=0.125, \mathrm{p}=0.039)$, fibrinogen $(\mathrm{r}=0.356, \mathrm{p}<0.001)$ and A1AT $(\mathrm{r}=0.194, \mathrm{p}<0.001)$. In our COPD patients, CRP and IL- 6 were inversely related to postbronchodilator $\mathrm{FEV}_{1}$ (\% predicted). However, the contribution of systemic inflammation to lung function decline is less clear. While crossectional studies show that systemic inflammatory markers are inversely related to lung function $[6,13,25]$, a prospective evaluation of lung function decline in a randomly selected population did not identify this negative effect over a 9-year period [34].

Finally, we found that exercise tolerance, as assessed by the distance walked in the 6-minute test was inversely related to serum CRP, IL- 6 and IL- 8 levels. IL- 6 is produced by contracting muscles and released into the blood, acting as an energy sensor. When contracting muscles are low in glycogen, IL- 6 gene transcription is increased and IL-6 is released to increase glucose uptake and induce lipolysis [35]. When muscles are exposed to oxidative stress, both IL- 6 mRNA and IL- 6 protein expression are enhanced [35]. It is known that COPD patients with high plasma levels of CRP had more 

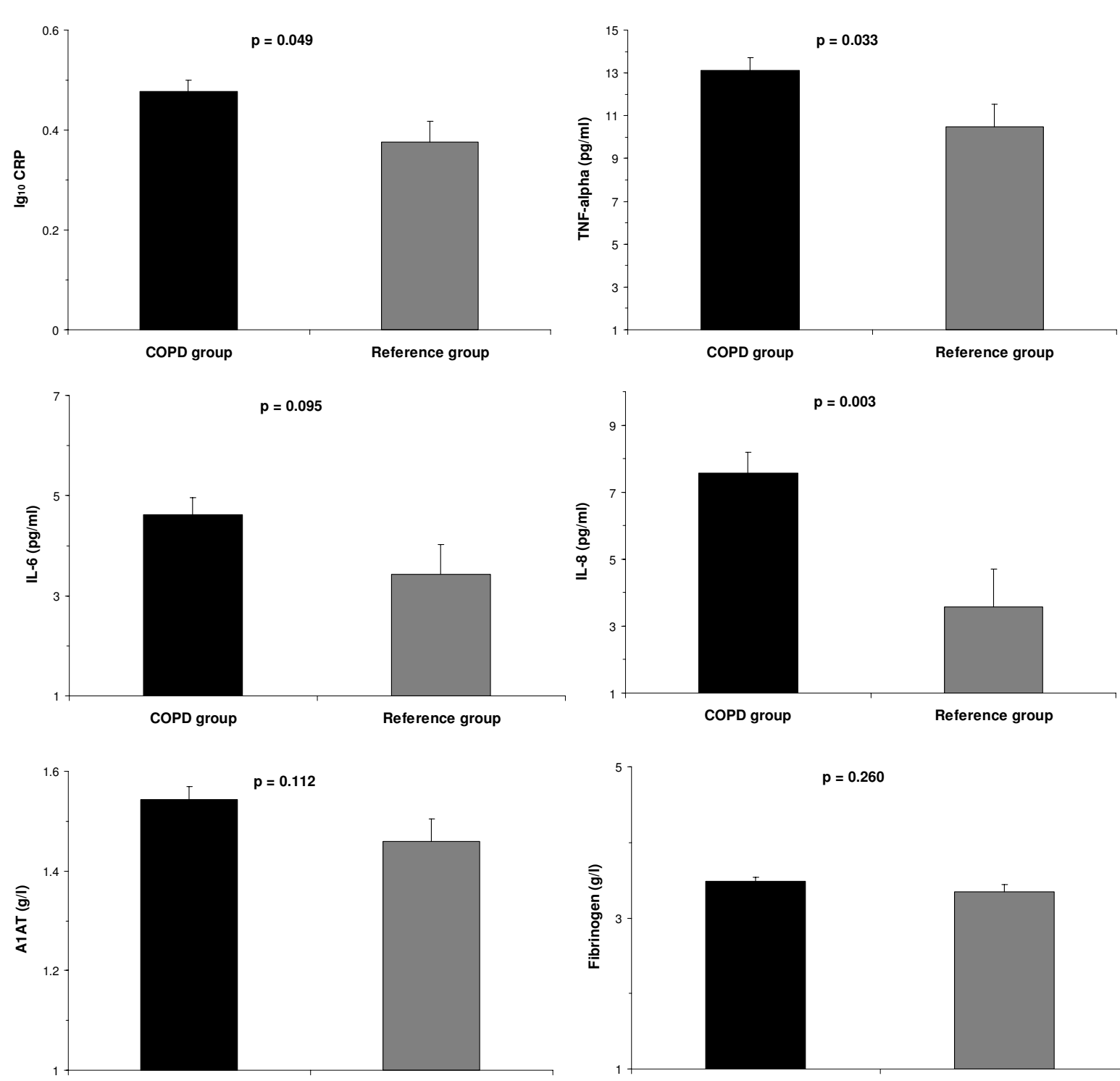

$p=0.112$
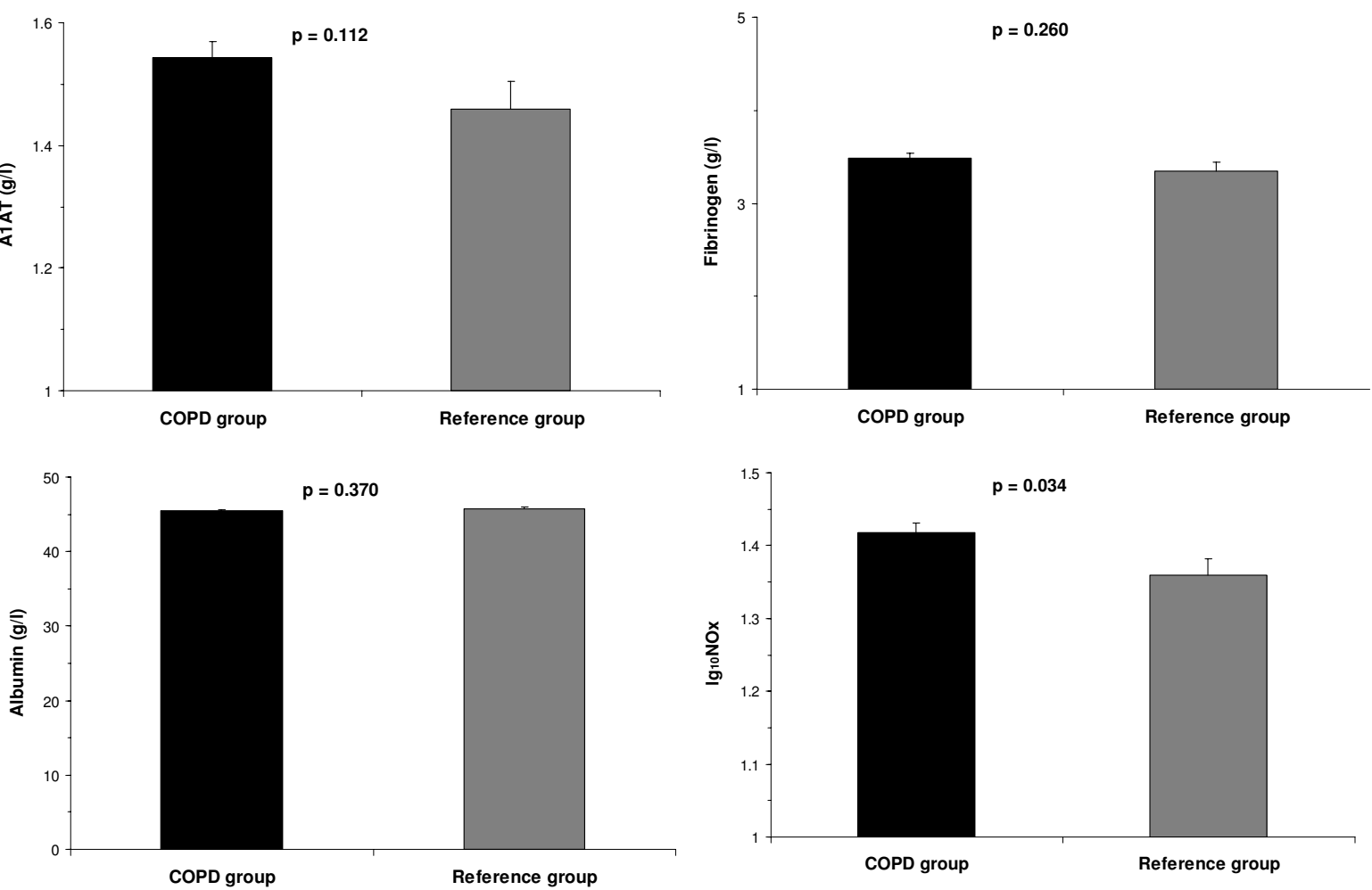

Figure 3 Serum concentrations of systemic biomarkers in COPD patients and control subjects. Data are presented as mean adjusted for age, sex, pack-years of smoking and body-mass index (standard error of the mean). A logarithmic transformation was used for $C R P$ and $\mathrm{NO}_{\mathrm{x}}$. Abbreviations: $\mathrm{CRP}=\mathrm{C}$-reactive protein; TNF = tumor necrosis factor; $\mathrm{LL}=$ interleukin; $\mathrm{A} 1 \mathrm{AT}=$ alpha- 1 antitrypsin; $\mathrm{NO}_{\mathrm{x}}=$ nitrites/nitrates. 
Table 4: Distribution of systemic biomarkers by severity of COPD according to GOLD criteria *

\begin{tabular}{|c|c|c|c|c|}
\hline & $\begin{array}{c}\text { Mild COPD } \\
(n=177)\end{array}$ & $\begin{array}{c}\text { Moderate COPD } \\
\quad(n=128)\end{array}$ & $\begin{array}{c}\text { Severe COPD } \\
(n=19)\end{array}$ & $p$ \\
\hline Male (\%) & 67.8 & 82.0 & 84.2 & 0.012 \\
\hline Age $(y r)$ & $62(54-70)$ & $67(58-73) \dagger$ & $70(66-74) \dagger$ & 0.003 \\
\hline $\mathrm{BMI}\left(\mathrm{Kg} / \mathrm{m}^{2}\right)$ & $27.4(4.7)$ & $28.5(4.7)$ & $28.7(6.4)$ & 0.107 \\
\hline Smoking status & & & & 0.135 \\
\hline Never smoker & 37.6 & 37.5 & 21.1 & \\
\hline Former smoker & 37.9 & 46.1 & 63.2 & \\
\hline Current smoker & 24.3 & 16.4 & 15.8 & \\
\hline Smoking exposure (packs-year) & $30(20-47)$ & $45(30-60) \neq$ & $40(22-54)$ & 0.001 \\
\hline C-reactive protein (mg/l) & $3.0(2.0-5.0)$ & $3.0(2.0-6.0)$ & $2.0(2.0-12.0) \neq$ & 0.007 \\
\hline TNF-alpha (pg/ml) & $10.0(7.0-14.0)$ & $11.0(8.0-18.0) \dagger$ & $11.0(5.0-14.0)$ & 0.017 \\
\hline IL-6 (pg/ml) & $1.9(1.9-3.0)$ & $1.9(1.9-7.0)$ & $3.0(1.9-16.0) \dagger$ & 0.008 \\
\hline IL-8 (pg/ml) & $2.0(0.7-7.8)$ & $2.0(0.7-10.0)$ & $7.0(0.9-11.0)$ & 0.323 \\
\hline Alpha-1 antitrypsin (g/l) & $1.47(1.27-1.72)$ & $1.47(1.32-1.73)$ & $1.59(1.38-1.83)$ & 0.706 \\
\hline Fibrinogen $(\mathrm{g} / \mathrm{l})$ & $3.46(1.04)$ & $3.63(1.11)$ & $3.73(1.17)$ & 0.305 \\
\hline Albumin (g/l) & $45.36(2.54)$ & $45.41(3.03)$ & $44.67(3.51)$ & 0.571 \\
\hline Nitrites/nitrates (nmol/l) & $26.3(20.8-38.1)$ & $23.3(19.1-31.2)$ & $27.1(17.7-61.8)$ & 0.048 \\
\hline
\end{tabular}

* Values are mean (SD) or median (interquartile range) depending on the distribution. Abbreviations: $\mathrm{TNF}=$ tumour necrosis factor; $\mathrm{IL}=$ interleukin. Comparisons between groups by ANOVA with Bonferroni test: $\uparrow p<0.05$ vs. mild COPD; $\neq p<0.01$ vs. mild COPD; $p<0.05$ vs. moderate COPD; § $\mathrm{p}<0.01$ vs. moderate COPD.

impaired energy metabolism, increased disability and more distress due to respiratory symptoms than patients with normal CRP levels [35]. Moreover, the relation between serum CRP levels and exercise tolerance seems to be independent of other factors such as age, sex, and smoking history [36]. Whether skeletal muscle dysfunction is a direct consequence of the systemic effects of the COPD or an independent process that contributes to the systemic inflammatory load of the disease, our results indicate that systemic biomarker levels could indirectly reflect the exercise capacity of these patients.

\section{Strengths and weakness of the study}

The strengths of this study include its population-based design, the use of post-bronchodilator spirometry as diagnostic criteria and the detailed characterization of the participants which allowed us to investigate factors associated with circulating biomarker levels. In addition to the post-bronchodilator spirometric criteria confirming the existence of an irreversible obstruction, in our never-smoker COPD patients there was evidence of the existence of a particular exposure history that could support the diagnosis.

Although it has been reported that the fixed $\mathrm{FEV}_{1} / \mathrm{FVC}$ ratio method results in a greater proportion of COPD diagnoses than other alternative methods, especially in the elderly, it still continues to be the criterion established in the GOLD guidelines and is certainly the most widely used in clinical practice. The current debate about LLN as an alternative to the fixed ratio is based more on the opinions of experts $[37,38]$ than on the existence of clear evidence. In this situation, the information provided by the Cardiovascular Health Study is especially relevant, demonstrating that a cohort of elderly subjects classified as "normal" using the LLN but abnormal using the fixed ratio were more likely to die and to have a COPD-related hospitalization during an 11-year follow-up [39]. Thus, a fixed $\mathrm{FEV}_{1} / \mathrm{FVC}$ ratio $<0.70$ may identify at-risk patients, even among older adults.

There are several potential limitations of our study worth discussing. Firstly, our COPD patient sample does not turn out to be necessarily representative of the COPD regularly seen in clinical practice. Due to the design of the present study, and to avoid the confusion by comorbidities, patients with several associated illnesses were excluded from the analysis. This strategy probably reduces differences between the two study groups, but it assures a stricter evaluation of these. Secondly, there were significant differences between COPD patients and reference subjects for anthropometric characteristics and smoking status. These are consequences of the population-based extraction of our study subjects and are partly 
Table 5: Comparison of systemic biomarkers by severity of COPD according to quartiles of BODE index*.

\begin{tabular}{|c|c|c|c|c|}
\hline & $\begin{array}{c}\text { Quartile } 1 \\
(n=282)\end{array}$ & $\begin{array}{c}\text { Quartile } 2 \\
(n=19)\end{array}$ & $\begin{array}{c}\text { Quartiles 3-4 } \\
(n=12)\end{array}$ & $p$ \\
\hline Male (\%) & 73.8 & 84.2 & 58.3 & 0.279 \\
\hline Age (yr) & $60(55-71)$ & $72(69-75) \dagger$ & $66(61-72)$ & 0.007 \\
\hline $\mathrm{BMI}\left(\mathrm{Kg} / \mathrm{m}^{2}\right)$ & $27.7(4.3)$ & $29.9(8.0)$ & $31.1(8.2) \dagger$ & 0.011 \\
\hline Smoking status & & & & 0.303 \\
\hline Never smoker & 38.3 & 31.6 & 16.7 & \\
\hline Former smoker & 41.1 & 57.9 & 50.0 & \\
\hline Current smoker & 20.6 & 10.5 & 33.3 & \\
\hline Smoking exposure (packs-year) & $40(25-50)$ & $50(23-85)$ & $50(32-59)$ & 0.050 \\
\hline C-reactive protein (mg/dl) & $3.0(2.0-5.0)$ & $3.0(2.0-6.0)$ & $4.5(2.0-24.7) \neq \S$ & 0.0001 \\
\hline TNF-alpha (pg/ml) & $10.0(7.0-14.5)$ & $11.0(8.5-16.0)$ & $12.0(7.7-15.0)$ & 0.992 \\
\hline IL-6 (pg/ml) & $1.9(1.9-4.0)$ & $3.0(1.9-12.0)$ & $2.5(1.9-12.0)$ & 0.032 \\
\hline IL-8 (pg/ml) & $2.0(0.7-8.0)$ & $7.0(4.0-13.0)$ & $10.5(0.7-25.2) \dagger$ & 0.004 \\
\hline Alpha-1 antitrypsin (g/l) & $1.46(1.29-1.69)$ & $1.56(1.24-1.72)$ & $1.69(1.56-1.84)$ & 0.444 \\
\hline Fibrinogen (g/l) & $3.54(1.06)$ & $3.66(1.29)$ & $3.93(1.14)$ & 0.446 \\
\hline Albumin $(\mathrm{g} / \mathrm{l})$ & $45.39(2.73)$ & $44.06(3.49)$ & $45.75(2.34)$ & 0.122 \\
\hline Nitrites/nitrates $(\mathrm{nmol} / \mathrm{l})$ & $24.9(19.7-34.2)$ & $29.5(20.1-35.4)$ & $22.4(16.4-83.2) \dagger$ & 0.030 \\
\hline
\end{tabular}

* Values are mean (SD) or median (interquartile range) depending on the distribution. Abbreviations: TNF = tumour necrosis factor; IL = interleukin. Comparisons between groups by ANOVA with Bonferroni test: $\uparrow p<0.05$ vs. quartile $1, \neq p<0.01$ vs. quartile 1 ; $p<<0.01$ vs. quartile 2.

a reflection of the fact that some differences are likely manifestations of the disease. Although the statistical model aims to adjust for these possible confounding factors, the existence of some uncontrolled effects cannot be excluded. And finally, this is a cross-sectional study, and inference of causality is not possible. Our results could also be affected by other drawbacks. Of the COPD patients in our study, 23\% were using inhaled corticosteroids. This could contribute to the underestimation of the difference in systemic biomarkers between COPD patients and control subjects. Nevertheless, the effect of inhaled corticosteroids on inflammatory biomarkers is still controversial. In patients with moderate to severe COPD, it has been reported that one month of fluticasone did not reduce serum CRP or IL-6 levels [28]. Other chronic conditions, such as chronic heart failure or diabetes, also appear to be associated with a similar lowgrade systemic inflammatory process [22]. Several studies have described that these disorders are more frequent in COPD patients and, therefore, might also contribute to their proinflammatory state. Nevertheless, and in order to analyze only the effect of COPD as an independent factor, we have carefully excluded these conditions from the present study.

\section{Conclusions}

This study provides information about the populationbased distribution of some systemic biomarkers according to lung function and BODE index, and reinforces the evidence that COPD is independently associated with low-grade systemic inflammation, with a different inflammatory pattern than the one observed in healthy subjects. In addition to its contribution to the extrapulmonary effects of COPD, the intensity of the systemic inflammation is directly related to the poorer quality of life, airflow limitation and exercise intolerance observed in COPD. These results emphasize the importance of carrying out multidimensional evaluations of COPD patients, of interest to understanding the mechanisms involved in COPD development and progression, as well as for the management of individual patients.

\section{Competing interests}

GS is a full-time employee of GlaxoSmithKline, drug manufacturerand sponsor of the study. However, the subject of the studyis epidemiological with no drugs involved. The rest of authorsdo not have any conflict of interest with relation to the contentsof the manuscript.

\section{Authors' contributions}

FGR served as the primary author, reviewing all data, and wrote the article. MM, JBS, LM, EDT, GS, VS and JA developed the study protocol, interpreted study data, contributed to and reviewed drafts of the manuscript, and approved the final version of the manuscript. All authors read and approved the final manuscript. The academic authors vouch for the veracity and completeness of the 


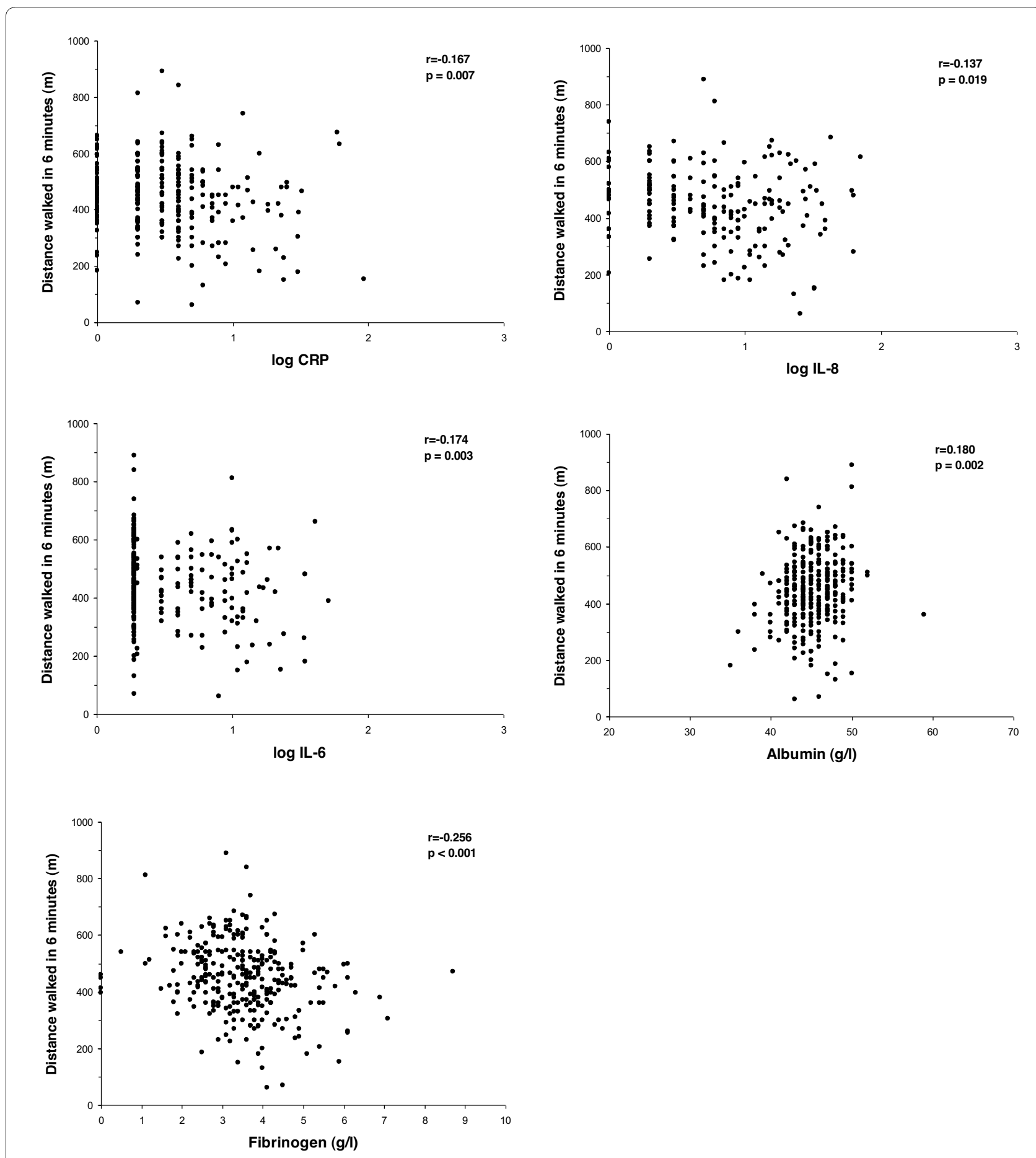

Figure 4 Relationship between serum concentrations of biomarkers and distance walked in 6-minutes in COPD patients. Abbreviations: CRP $=$ C-reactive protein; $\mathrm{L} \mathrm{L}=$ interleukin; $r$ = Pearson's linear bivariate correlation coefficient.

data and the data analyses. The study sponsor did not place any restrictions with regard to statements made in the final version of the article.

\section{Acknowledgements}

Funding was provided by GlaxoSmithKline. The EPI-SCAN Steering Committee, comprising seven academics and one representative of the sponsor, developed the design and concept, approved the statistical analysis plan, had full access to and interpreted the data, wrote the article, and was responsible for decisions with regard to publication.

We thank the staff and participants in the EPI-SCAN study, and particularly Mónica Sarmiento (IMS Health Economics and Outcomes Research, Barcelona, Spain) for the monitoring anddata management of the study. 


\section{EPI-SCAN Team}

\section{Author Details}

IPneumology Service, Hospital Universitario La Paz, IdiPAZ, Madrid, Spain, ${ }^{2}$ Fundació Clinic, Institut d'Investigacions Biomèdiques August Pi I Sunyer

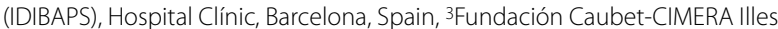
Balears, Bunyola, Illes Balears, and CIBER de Enfermedades Respiratorias, Spain, 4Pneumology Department, Hospital Reina Sofía, Córdoba, Spain, 5IMIM/CREAL Barcelona, Spain, ${ }^{\circ}$ Medical Department, GlaxoSmithkline S.A., Madrid, Spain,

7 Pneumology Department, Hospital de Cruces, Bilbao, Spain and

8Pneumology Department, Hospital La Princesa, Madrid, Spain

Received: 26 January 2010 Accepted: 25 May 2010

Published: 25 May 2010

\section{References}

1. Schols AM, Slangen J, Volovics L, Wouters EF: Weight loss is a reversible factor in the prognosis of chronic obstructive pulmonary disease. Am J Respir Crit Care Med 1998, 157:1791-1797.

2. Maltais F, Simard AA, Simard C, Jobin J, Desgagnés P, LeBlanc P: Oxidative capacity of the skeletal muscle and lactic acid kinetics during exercise in normal subjects and in patients with COPD. Am J Respir Crit Care Med 1996, 153:288-293.

3. Agustí A: Systemic effects of chronic obstructive pulmonary disease: what we know and what we don't know (but should). Proc Am Thorac Soc 2007, 4:522-525.

4. Fabbri LM, Rabe KF: From COPD to chronic systemic inflammatory syndrome? Lancet 2007, 370:797-799.

5. Mannino DM, Ford ES, Redd SC: Obstructive and restrictive lung disease and markers of inflammation: Data from the third national health and nutrition examination. Am J Med 2003, 114:758-762.

6. Dahl M, Tybjaerg-Hansen A, Vestbo J, Lange P, Nordestgaard BG: Elevated plasma fibrinogen associated with reduced pulmonary function and increased risk of chronic obstructive pulmonary disease. Am J Respir Crit Care Med 2001, 164:1008-1011.

7. Rahman I, Morrison D, Donaldson K, MacNee W: Systemic oxidative stress in asthma, COPD, and smokers. Am J Respir Crit Care Med 1996, 154:1055-1060.

8. Gan WQ, Man SF, Senthilselvan A, Sin DD: Association between chronic obstructive pulmonary disease and systemic inflammation: a systematic review and a meta-analysis. Thorax 2004, 59:574-580.

9. Rabe KF, Hurd S, Anzueto A, Barnes PJ, Buist SA, Calverley P, Fukuchi Y, Jenkins C, Rodríguez-Roisin R, van Weel C, Zielinski J, Global Initiative for Chronic Obstructive Lung Disease: Global strategy for the diagnosis, management, and prevention of chronic obstructive pulmonary disease: GOLD executive summary. Am J Respir Crit Care Med 2007, 176:532-555.

10. Franciosi LG, Page CP, Celli BR, Cazzola M, Walker MJ, Danhof M, Rabe KF, Della Pasqua OE: Markers of disease severity in chronic obstructive pulmonary disease. Pulm Pharmacol Therap 2006, 19:189-199.

11. Shaaban R, Kony S, Driss F, Leynaert B, Soussan D, Pin I, Neukirch F, Zureik $\mathrm{M}$ : Change in C-reactive protein levels and FEV decline: A longitudinal population-based study. Respir Med 2006, 100:2112-2120.

12. Senn O, Russi EW, Schindler C, Imboden M, von Exkardstein A, Brändli O, Zemp E, Ackermann-Liebrich U, Berger W, Rochat T, Luisetti M, ProbstHensch NM: Circulating alpha 1-antitrypsin in the general population: Determinants and association with lung function. Respir Res 2008, 9:35.

13. Thorleifsson SJ, Margretardottir OB, Gudmundsson G, Olafsson I, Benediktsdottir B, Janson C, Buist AS, Gislason T: Chronic airflow obstruction and markers of systemic inflammation: Results from the BOLD study in Iceland. Respir Med 2009, 103:1548-1553.

14. van Durme YMTA, Verhamme KMC, Aarnoudse AJLHJ, Van Pottelberge GR, Hofman A, Witteman JCM, Joos GF, Brusselle GG, Stricker BHC: C-reactive protein levels, haplotypes, and the risk of incident chronic obstructive pulmonary disease. Am J Respir Crit Care Med 2009, 179:375-382.

15. Ancochea J, Badiola C, Duran-Tauleria E, Garcia-Rio F, Miravitlles M, Muñoz L, Sobradillo V, Soriano JB: The EPI-SCAN survey to assess the prevalence of chronic obstructive pulmonary disease in Spanish 40-to-80-yearolds: protocol summary. Arch Bronconeumol 2009, 45:41-47.

16. Miravitlles M, Soriano JB, Garcia-Rio F, Muñoz L, Duran-Tauleria E, Sanchez $G$, Sobradillo V, Ancochea J: Prevalence of COPD in Spain and impact of undiagnosed COPD on quality of life and daily life activities. Thorax 2009, 64:863-868

17. Celli BR, Cote CG, Marin JM, Casanova C, Montes de, Oca M, Mendez RA, Pinto Plata V, Cabral HJ: The body-mass index, airflow obstruction, dyspnea, and exercise capacity index in chronic obstructive pulmonary disease. N Eng/ J Med 2004, 350:1005-1012.

18. Miller MR, Hankinson J, Brusasco V, Burgos F, Casaburi R, Coates A, Crapo $R$, Enright P, Grinten CP van der, Gustafsson P, Jensen R, Jonson DC, MacIntyre N, McKay R, Navajas D, Pedersen OF, Pellegrino R, Viegi G, Wanger J: Standardization of spirometry. Eur Respir J 2005, 26:319-338.

19. Roca J, Sanchis J, Agustí-Vidal A, Segarra F, Navajas D, Rodríguez-Roisin R, Casan P, Sans S: Spirometric reference values from a Mediterranean population. Bull Eur Physiopathol Respir 1986, 22:217-224.

20. ATS Statement: Guidelines for the six-minute walk test. Am J Respir Crit Care Med 2002, 166:111-116.

21. Snijders T, Bosker R: Multilevel analysis: an introduction to basic and advanced multilevel modeling London: Sage; 1999

22. De Martinis M, Franceschi C, Monti D, Ginaldi L: Inflamm-ageing and lifelong antigenic load as major determinants of ageing rate and longevity. FEBS Lett 2005, 579:2035-2039.

23. Ben-Zaken Cohen S, Paré PD, Man SFP, Sin DD: The growing burden of chronic obstructive pulmonary disease and lung cancer in women. Examining sex differences in cigarette smoke metabolism. Am J Respir Crit Care Med 2007, 176:113-120.

24. Vernooy JH, Kucukaycan M, Jacobs JA, Chavannes NH, Buurman WA, Dentener MA, Wouters EF: Local and systemic inflammation in patients with chronic obstructive pulmonary disease: soluble tumor necrosis factor receptors are increased in sputum. Am J Respir Crit Care Med 2002, 166:1218-1224.

25. Walter RE, Wilk JB, Larson MG, Vasan RS, Keaney JF Jr, Lipinska I, O'Connor GT, Benjamin EJ: Systemic Inflammation and COPD. The Framingham Heart Study. Chest 2008, 133:19-25.

26. Franssen FM, O'Donnell DE, Goossens GH, Blaak EE, Schols AM: Obesity and the lung: 5. Obesity and COPD. Thorax 2008, 63:1110-1117.

27. De Torres JP, Cordoba-Lanus E, López-Aguilar C, Muros de Fuentes M, Montejo de Garcini A, Aguirre-Jaime A, Celli BR, Casanova C: C-reactive protein levels and clinically important predictive outcomes in stable COPD patients. Eur Respir J 2006, 27:902-907.

28. Sin DD, Man SF, Marciniuk DD, Ford G, FitzGerald M, Wong E, York E, Mainra RR, Ramesh W, Melenka LS, Wilde E, Cowie RL, Williams D, Gan WQ Rousseau R: The effects of fluticasone with or without salmeterol on systemic biomarkers of inflammation in chronic obstructive pulmonary disease. Am J Respir Crit Care Med 2008, 177:1207-1214.

29. Barnes PJ: Chronic obstructive pulmonary disease. N Engl J Med 2000, 343:269-280.

30. Vliet A Van der, Eiserich JP, Shigenaga MK, Cross CE: Reactive nitrogen species and tyrosine nitration in the respiratory tract. Am J Respir Crit Care Med 1999, 160:1-9.

31. Sin DD, Man SF: Why are patients with chronic obstructive pulmonary disease at increased risk of cardiovascular diseases? The potential role of systemic inflammation in chronic obstructive pulmonary disease. Circulation 2003, 107:1514-1519.

32. Hansell AL, Walk JA, Soriano JB: What do chronic obstructive pulmonary disease patients die from? A multiple cause coding analysis. Eur Respir J 2003, 22:809-814

33. Dahl M, Vestbo J, Lange P, Bojesen SE, Tybjærg-Hansen A, Nordestgaard $\mathrm{BG}$ : C-reactive protein as a predictor of prognosis in chronic obstructive pulmonary disease. Am J Respir Crit Care Med 2007, 175:250-255.

34. Fogarty AW, Jones S, Britton JR, Lewis SA, McKeever TM: Systemic inflammation and decline in lung function in a general population: a prospective study. Thorax 2007, 62:515-520.

35. Broekhuizen R, Wouters EFM, Creutzberg EC, Schols AMWJ: Raised CRP levels mark metabolic and functional impairment in advanced COPD. Thorax 2006, 61:17-22.

36. Pinto-Plata VM, Mullerova H, Toso JF, Feudjo-Tepie M, Soriano JB, Vessey RS, Celli BR: C-reactive protein in patients with COPD, control smokers and non-smokers. Thorax 2006, 61:23-28.

37. Mannino D: Defining chronic obstructive pulmonary disease... and the elephant in the room. Eur Respir J 2007, 30:189-19.

38. Pellegrino R, Brusasco V, Viegi G, Crapo RO, Burgos F, Casaburie R, Coates A, Grinten CPM van der, Gustafsson P, Hankinson J, Jensen R, Johnson DC, 
MacIntyreee N, McKay R, Miller MR, Navajas D, Pedersen OF, Wanger J: Definition of COPD: based on evidence or opinion? Eur Respir J 2008, 31:681-69.

39. Mannino DM, Buist AS, Vollmer WM: Chronic obstructive pulmonary disease in the older adult: what defines abnormal lung function? Thorax 2007, 62:237-241.

doi: 10.1186/1465-9921-11-63

Cite this article as: Garcia-Rio et al., Systemic inflammation in chronic obstructive pulmonary disease: a population-based study Respiratory Research 2010, 11:63

Submit your next manuscript to BioMed Central and take full advantage of:

- Convenient online submission

- Thorough peer review

- No space constraints or color figure charges

- Immediate publication on acceptance

- Inclusion in PubMed, CAS, Scopus and Google Scholar

- Research which is freely available for redistribution

Submit your manuscript at www.biomedcentral.com/submit 